\title{
Interactive comment on "Implementation of salt-induced freezing point depression function into CoupModel_v5 for improvement of modelling seasonally frozen soils" by Mousong Wu et al.
}

\section{Anonymous Referee \#2}

Received and published: 19 March 2019

Summary: The authors have presented a study in which they modify the CoupModel to consider the effects of dissolved solutes on the soil-water freezing point depression. The study is, for the most part, a valuable contribution to the field of cold regions hydrological modeling. However, the structure of the manuscript makes it hard to follow in many places. A clearer description of the model processes is needed, and the results and discussion need to be split into two separate sections. There are also many small grammatical errors throughout, I have highlighted some but there were too many for me to individually address.

I also have somewhat of an issue with the entire approach to this kind of modeling. The 
authors incorporate a new process in the model, but rather than systematically testing the impact of the new physics on the model outputs against simple test cases that isolate the effect of one process on another, they authors try to simulate a field experiment with a multitude of different and interacting processes. An alternative approach would have been to simulate a much simpler, highly controlled experiment (for e.g. the authors could have simulated the soil column experiment of Stähli and Stadler (1997)), to test the performance of the newly implemented freezing-point depression relation. After that the authors could have applied their model to their field site. However, I admit this is a philosophical difference of opinion and there are other researchers who would advocate for this approach. Thus, I only bring up this point for the consideration of the associate editor. I believe the content of the article fits well within the scope of HESS and could be useful for the targeted audience. However, in my opinion, the manuscript could be suitable for publication in HESS only after major revisions are done to the structure and quality of writing of the manuscript.

General comments:

Lines 131 - 135: Did this pre-calibrated relationship consider the in-situ soil salinity already present and its effect in the electrical potential of the soil water? If the soils at both sites are affected by salinization issues, then wouldn't in-situ salinity be an important consideration? More discussion of this is warranted. Furthermore, was any in-situ salinity measured? This could potentially a major issue in the field data collection. Can the authors give reason as to why this was not attempted? Possibly due to equipment trouble?

Lines 158 - 164: Was a sensitivity test carried out to ensure model discretization and time-stepping choices did not affect the numerical solution? In my experience, when modeling water partitioning at the soil surface, node spacing may sometimes have to be smaller than $10 \mathrm{~cm}$.

Lines 258-260: Why was initial salt concentration, precipitation salt concentration and

Printer-friendly version

Discussion paper
Interactive

comment 
irrigation salt concentration used calibration parameters? Couldn't these numbers be obtained from the site measurements? I have an issue with the initial salt concentration being used a calibration parameter, it will obviously influence the tracer transport. This brings me back to my earlier point amount measuring the in-situ salinity of the soil. It is also possible to estimate soil salinity using TDR (e.g. Stähli and Stadler, 1997). One could also envision the initial salt concentration profile being estimated from the change in electrical conductivity after the initial application of the $\mathrm{Br}$ - tracer.

Section 3: This section in general is written in a rather convoluted manner and is not the easiest for the reader to understand. In general, I think the entire section 3 needs to be rewritten to address the many grammatical issues and lack of clarity in the description of the processes and model calibration/validation approach.

Section 3: I think the authors need to more clearly emphasize that they employ both Esbey's (1992) bypass flow routine as well as Stahli et al.'s (1996) dual-domain hydraulic conductivity concept to simulate water flow in frozen soil, i.e. you have high and low flow domains in the soil matrix and additional by-pass flow through macropores. The authors need to careful to clearly identify the different processes being simulated as there is overlap in the terminology used to described different processes in the model. For example, in lines $182-184$ you use the term high-flow domain to describe the bypass routine's ability to route water directly in the underlying soil layer when the infiltration capacity of the soil matrix is reached. However, you also you the term high-flow domain in lines $196-199$ to describe the frozen soil hydraulic conductivity model of Stahli et al. (1996). Thus, you need to be very clear about which frozen soil flow process you are describing. It must also be noted that this approach, while rather complex, still has its conceptual limitations as refreezing of infiltrated water can also occur in macropores (Watanabe and Kugisaki, 2017). While the concept of Stähli et al. (1996) has widely been used to incorporate the effects of preferential flow and refreezing of infiltrated water, you also employ a by-pass flow routine which does not consider the effect of refreezing along macropores. Some discussion of this is war- 
ranted. See the recent review of Mohammed et al. (2018) on macropore flow in frozen soils.

Section 4: This section needs to be split into two separate Results and Discussion sections.

Line 447: The authors did not develop a new relationship, other frozen soil models (e.g. SHAW - Flerchinger Saxton (1989)) have long incorporated the relationship between osmotic potential and soil freezing temperature.

Lines 452 - 453: Again, it is not enough to simply state that they impact soil heat and water transport. How specifically does it impact heat and water transport?

Lines 511 - 513: More discussion the model misfit at lower depths is needed. From figure 8, at one site the model overestimates soil water at depth and at the other site it underestimates it. What are the reasons for this? Is it an improper representation of the vadose zone flow processes (as the authors include quite a complicated representation of the soil water flow processes) or a misrepresentation of the lower boundary condition and influence of groundwater, or some combination of both?

Lines 527 - 538: More discussion of the large difference in the model and measured salt storage is needed. What was the mass recovery of the applied $\mathrm{Br}$ - tracer relative to the application? This would give some insight into the flow processes affecting solute transport. For example, very little BR- was measured at the Qianguo site... was this due to leaving due to preferential flow to groundwater or increased retention of the tracer near the surface? This could also be a possible reason for your mismatch of soil water storage at deeper depths (see comment above).

Additional references: Espeby, B. 1992. Coupled simulations of water flow from a fieldinvestigated glacial till slope using a quasi-two-dimensional water and heat model with bypass flow. Journal of Hydrology 131:105-132.

Flerchinger, G.N., and K.E. Saxton. 1989. Simultaneous heat and water model of a

Printer-friendly version

Discussion paper 
freezing snow residue-soil system: 1 . Theory and development. Transactions of the ASAE 32:565-571.

Mohammed AA, Kurylyk BL, Cey EE, Hayashi M. 2018. Snowmelt infiltration and macropore flow in frozen soils: overview, knowledge gaps, and a conceptual framework. Vadose Zone Journal 17(1).

Stähli, M., P. Jansson, and L.C. Lundin. 1996. Preferential water flow in a frozen soil: A two-domain model approach. Hydrological Processes 10:1305-1316.

Stähli M, Stadler D. 1997. Measurement of water and solute dynamics in freezing soil columns with time domain reflectometry. Journal of Hydrology 195(1-4):352-369.

Watanabe, K., and Y. Kugisaki. 2017. Effect of macropores on soil freezing and thawing with infiltration. Hydrological Processes 31:270-278.

Technical corrections:

Abstract:

Line 15 - 16: Delete 'In this context' from the sentence, unnecessary.

Line 17: '... influences of salt on cold region hydrology' is too vague a statement. Reword to be more specific, for example: '... influences of soil salinity on soil water and heat transport'.

Line 18: Modify sentence to 'We modified the CoupModel to simulate the impacts of salinity on soil freezing point depression'.

Line 21: Delete words 'into CoupModel', unnecessary.

Line 26: Change 'provided' to 'provides'.

Printer-friendly version

Introduction:

Line 35: Awkwardly worded sentence, change to something along the lines of 'Knowledge on soil freezing and thawing is needed to better understand mechanisms...'.

Discussion paper 
Line 48: Change to '... in the two same agricultural fields in this study...'

Line 61: Should be '... agricultural fields'.

Line 62: Modify to '. . . and other cold region ecosystems'

Line 63: Should be 'However there are large uncertainties. ..'

Interactive

comment

Line 64: Modify to 'and coupled transport processes'.

Line $64-65$ : Modify sentence to '. . . uncertainty analysis methods have been utilized by....

Line 67: modify to '.. is a commonly used. ..'.

Line 70: Modify to 'GLUE is performed. ..'.

Line 75: Delete '.. in the northern part of China.' Redundant.

Line 86 - 87: Modify sentence to 'We modified the CoupModel to consider the impacts of salinity on soil freezing. ...

Line 89: Modify to '... 2) perform a sensitivity analysis on the new model'.

Line 90: Modify to '. . . in modeling hydrological process in seasonally frozen soils.'.

Material and Methods:

Line 93: Should be '. . . in northern China.'

Line 95: Should be 'Field experiments at. ..'

Line 128: Should be 'During the soil freeze-thaw period at. ..'

Line 192: you not describe what the $\mathrm{pF}$ value is.

Printer-friendly version

Line 229: Change to 'latent heat transfer:'

Line 257: Lateral boundaries? Isn't Coup a 1-D model? Why would it need a lateral

Discussion paper 
boundary condition?

Line 285: You refer to equation (5), but are talking about the surface energy balance, I think you meant equation (15).

Line 291: need a citation for the Richardson equation as readers may not be familiar with the relationship.

Line 323: I think you mean $\mathrm{H}$ is the total sensible heat stored in the soil, not total energy?

Results and Discussion:

Figure 3: Figure 3a should be modified to use solid circles like Figure 3b. It would make the Fig. $3 a$ easier to read.

Conclusions:

Line 543: Should be '. . a are coupled in agricultural fields'.

Line 566: Replace 'would be very necessary in investigation' to 'is still needed to improve understanding of'.

Please also note the supplement to this comment:

https://www.hydrol-earth-syst-sci-discuss.net/hess-2018-466/hess-2018-466-RC2supplement.pdf

Interactive comment on Hydrol. Earth Syst. Sci. Discuss., https://doi.org/10.5194/hess-2018466, 2018. 